\title{
A Case of Friction Alopecia in a Healthy 15-Year-Old Girl
}

\author{
Emilie Fowler Antonella Tosti \\ Department of Dermatology and Cutaneous Surgery, University of Miami Miller School of Medicine, Miami, FL, USA
}

\section{Established Facts}

- Friction alopecia is a non-scarring alopecia that can be self-inflicting (commonly reported as trichoteiromania) or caused by foreign objects.

- Findings of trichorrhexis nodosa on dermoscopy can lead to a wide differential diagnosis, including metabolic disorders or hair weathering.

\section{Novel Insights}

- In order to make a diagnosis of friction alopecia, it is important to take a detailed patient history along with performing a dermoscopic exam that can show some characteristic findings. Taking a thorough history is especially important in order to direct treatment towards the root cause.

\section{Keywords}

Alopecia $\cdot$ Dermoscopy $\cdot$ Hair $\cdot$ Hair disorder $\cdot$ Non-scarring alopecia $\cdot$ Pediatric hair disease

\begin{abstract}
Friction alopecia is a non-scarring alopecia that causes hair breakage and may cause trichorrhexis nodosa. We report a case of a 15-year-old girl with self-inflicting friction alopecia that demonstrated broken hairs and proximal trichorrhexis nodosa on dermoscopy. We review various causes of friction alopecia and clinical findings, as well as trichorrhexis nodosa.

(c) 2018 S. Karger AG, Basel
\end{abstract}

\section{KARGER}

(c) 2018 S. Karger AG, Basel

E-Mail karger@karger.com

www.karger.com/sad

\section{Case Report}

A 15-year-old girl presented for consultation of an alopecic patch of 3 months duration. Family history was negative for alopecia areata or other hair disorders.

Scalp examination (Fig. 1) showed an irregular $5 \times 3 \mathrm{~cm}$ alopecic patch on the left parietal scalp. The patch showed some new regrowing hairs in its distal portion. Dermoscopy showed short hairs with multiple irregular transverse white bands and proximal trichorrhexis nodosa (Fig. 2). There were no hair shaft abnormalities outside of the patch.

On further questioning, the patient revealed repetitively touching and scratching her hair while studying for tests. She was subsequently diagnosed with friction alopecia. She was treated with $\mathrm{N}$-acetylcysteine $600 \mathrm{mg}$ b.i.d. and showed improvement in hair regrowth on follow-up.
Emilie Fowler

Department of Dermatology and Cutaneous Surgery University of Miami School of Medicine

1600 NW 10th Avenue RMSB 2023A, Miami, FL 33136 (USA)

E-Mail ejf71@med.miami.edu 


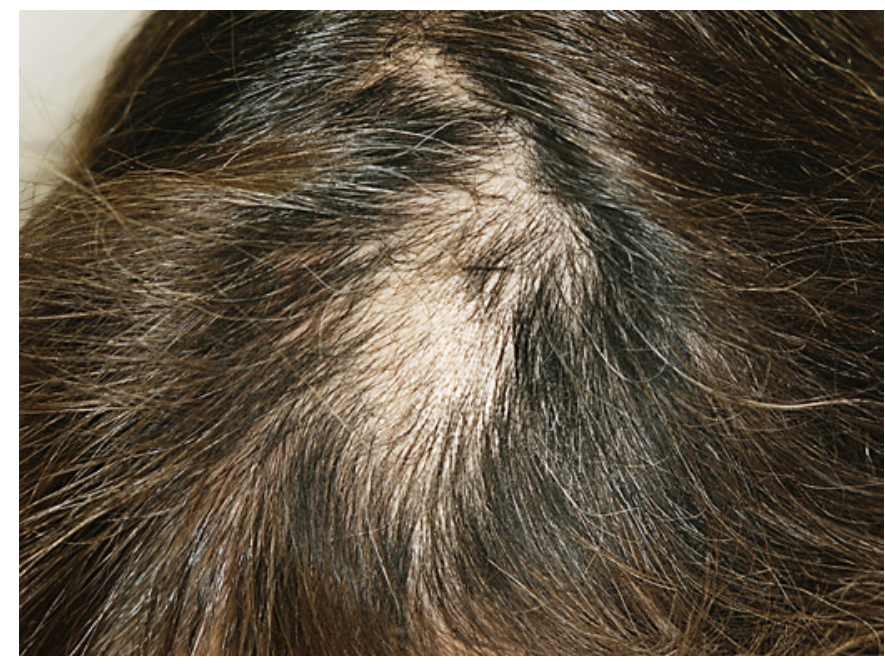

Fig. 1. $5 \times 3 \mathrm{~cm}$ alopecic patch located on the left parietal scalp.

\section{Discussion}

Friction alopecia is hair loss secondary to frequent rubbing of the hair, which leads to hair breakage at different levels and splitting at the ends [1,2]. It is a non-scarring alopecia that can be caused by a self-inflicting tic disorder or a foreign object rubbing on the hairs.

When it is self-inflicting, friction alopecia is referred to as trichoteiromania ("teiro" from the Greek derivation meaning "I rub"), a psychiatric disorder characterized by compulsive rubbing of the hair $[1,3]$. The hallmark feature of trichoteiromania is short, broken hairs with split, brush-like ends giving the appearance of white tips macroscopically [1]. This is the result of repetitive rubbing that gradually erodes the cuticular cell margins in the distal shaft (where they are less adherent) $[1,3]$. This brushlike splitting is not reported in trichotillomania (pulling of the hair) or trichotemnomania (cutting of the hair), differentiating trichoteiromania from the other self-induced alopecias [1]. Other potential findings include broken hair shafts of varying lengths and slight erythema in the areas affected [4].

Objects constantly rubbing on the hairs can cause friction alopecia. It has been described in the lower extremities of men in the distribution of their socks and shoes [5], as well as on the back of the lower extremities from waterslides [6], in gymnasts from balance beam events such as head stands and rollovers [7], and in a jogger wearing a tight-banded headphone on her scalp [8].

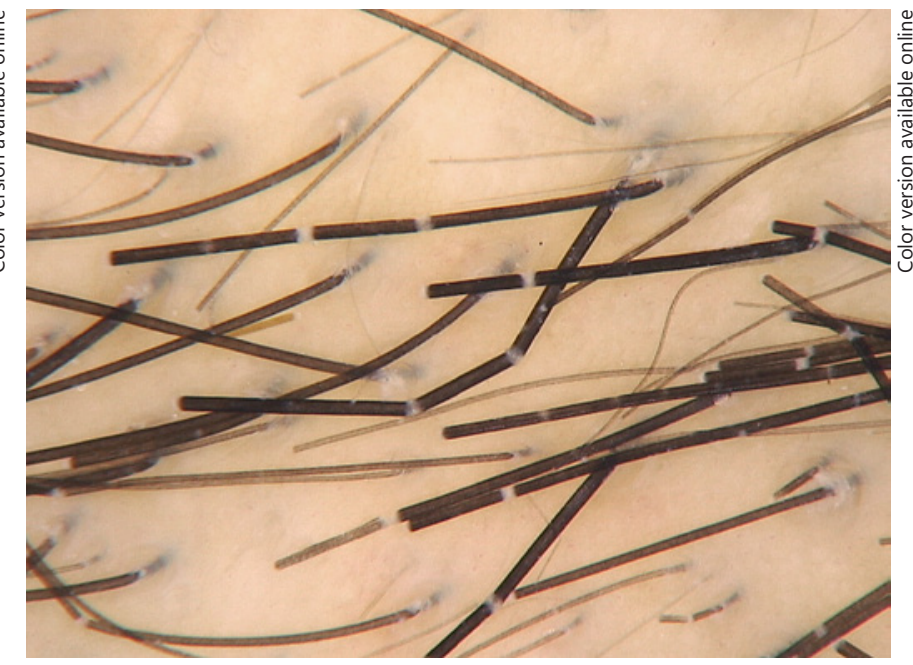

Fig. 2. Dermoscopic examination showing broken hairs with proximal trichorrhexis nodosa.

Owens and Chernosky [9] demonstrated that friction on the hair caused by rubbing can cause trichorrhexis nodosa. Trichorrhexis nodosa occurs when the hair shaft splits longitudinally into small fibers that bulge out causing the macroscopic appearance of small white nodules along the hair shaft [10]. At higher magnifications, this appears as two ends of a paintbrush pushed against one other. Although distal trichorrhexis nodosa is more common and due to hair weathering, intense scratching can cause findings of proximal trichorrhexis nodosa [11].

Rarely, trichorrhexis nodosa can be congenital, due to inherent underlying structural defects in the hair shaft that lead to breakage with minor trauma. Examples include argininosuccinate aciduria [12], phenylketonuria [13], or abnormalities of amino acid composition in the hair shaft [14]. These must be ruled out as differential diagnoses in children presenting with trichorrhexis nodosa as their systemic symptoms can be severe leading to dire consequences.

Prognosis of friction alopecia depends on recognition of the underlying cause. Patients suffering from trichoteiromania tend to deny any manipulation and may require excessive diagnostic procedures such as occlusive scalp dressings to prove the self-induced hair loss. Therapeutic management typically consists of mandatory and intense cooperation with a psychiatrist [15].
Fowler/Tosti 


\section{Statement of Ethics}

All procedures performed were in compliance with guidelines for human studies and animal welfare regulations. Consent was given for publication of photographs and details of the case.

\section{Disclosure Statement}

The authors declare no conflicts of interest.

\section{References}

1 Banky JP, Sheridan AT, Dawber RP: Weathering of hair in trichoteiromania. Australas J Dermatol 2004;45:186-188.

2 Miteva M, Romanelli P, Tosti A: Pigmented casts. Am J Dermatopathol 2014;36:58-63.

3 McMichael AJ, Hordinsky MK: The biopsychosocial aspects of hair disease: factitial hair loss. In: Hair and Scalp Diseases: Medical, Surgical, and Cosmetic Treatments. Boca Raton: CRC Press 2008, p 269.

4 Harth W, Blume-Peytavi U: Psychotrichology: psychosomatic aspects of hair diseases. J Dtsch Dermatol Ges 2013;11:125-135.

5 Zhao J, Cohen PR: Frictional alopecia of the distal legs: case series and review. Dermatol Online J 2016;22:pii: 13030/qt9hz9t0df.
6 Adams BB: Water-slide alopecia. Cutis 2001; 67:399-400.

7 Ely PH: Balance beam alopecia. Arch Dermatol 1978;114:968.

8 Copperman SM: Two new causes of alopecia. JAMA 1984;252:3367.

9 Owens DW, Chernosky ME: Trichorrhexis nodosa: in vitro reproduction. Arch Dermatol 1966;94:586-588.

10 Rudnicka L, Rakowska A, Kerzeja M, Olszewska M: Hair shafts in trichoscopy: clues for diagnosis of hair and scalp diseases. Dermatol Clin 2013;31:695-708.

11 Tosti A: Hair weathering. In: Dermoscopy of the Hair and Nails. 2nd ed. Boca Raton: CRC Press 2016, pp 101-107.
12 Fichtel JC, Richards JA, Davis LS: Trichorrhexis nodosa secondary to argininosuccinicaciduria. Pediatr Dermatol 2007;24:25-27.

13 Donati A, Vincenzi C, Tosti A: Acute hair loss in phenylketonuria. J Eur Acad Dermatol Venereol 2009;23:613-615.

14 Blume-Peytavi U, Fohles J, Schulz R, Wortmann G, Gollnick H, Orfanos CE: Hypotrichosis, hair structure defects, hypercysteine hair and glucosuria: a new genetic syndrome? Br J Dermatol 1996;134:319-324.

15 Reich S, Trüeb RM: Trichoteiromania (in German). J Dtsch Dermatol Ges 2003;1:2228. 